\title{
Loco-regional therapy for metastatic breast cancer
}

Curative treatment is not possible for most patients with metastatic breast cancer (MBC) because cancer cells have spread throughout the body (1). The main treatment aims are to 'prolong survival and palliate symptoms'. Systemic therapy can achieve these aims by reducing and suppressing tumor growth. Hormone therapy, chemotherapy and molecular targeted agents are administered, according to their predicted efficacies, as systemic treatments. Recently, immune check point blockade agents (ICI) have been shown to prolong the survival of patients with triple negative breast cancer (2), which has a poorer prognosis than other breast cancer subtypes and is resistant to standard systemic treatments. Patients with MBC can survive longer without metastatic symptoms when treated with these systemic therapies. However, MBC cannot be cured with ICI or other treatments and the majority of MBC patients will die of their disease. It is important to use all available treatments to obtain maximal control of symptoms, prevent serious complications, and prolong life with minimal disruption of daily activities and quality of life (3). We endeavor to use fewer powerful drugs, such as hormone therapy and oral agents, and thereby minimize severe adverse events.

Loco-regional therapy including surgery, radiation and interventional radiotherapy are useful for preventing local symptoms caused by tumors. However, definitive evidence that loco-regional therapy for MBC can prolong the survival is, as yet, lacking (4). Loco-regional therapies have been regarded as intensive treatment associated with several complications. Thus, we did not aggressively use loco-regional therapies for MBC patients without symptoms. At present, we can administer loco-regional therapy safely and to a limited extent, and still achieve meaningful clinical improvements.

In addition, there have been remarkable advances in diagnostic imaging examinations. We can now detect extremely small metastases that previously could not be visualized employing traditional imaging modalities (5).

'Oligometastasis' is a concept that is currently being debated (6). According to this concept, even distant metastases, depending on their location and number, can potentially be cured with an aggressive treatment strategy including locoregional therapy. If we use the most advanced imaging examinations available as intensive follow-up, we can detect more oligometastases. Currently, intensive routine radiographic investigations for distant metastasis in asymptomatic patients are not recommended, because data supporting prognostic benefits are lacking (7). We need to re-evaluate the data regarding the effectiveness of modern loco-regional therapy for oligometastatic disease. Improved treatment for oligometastases is anticipated to advance the total treatment strategy for MBC.

\section{Acknowledgments}

Funding: None.

\section{Footnote}

Provenance and Peer Review: This article was commissioned by the editorial office, Translational Cancer Research, for the series "Loco-regional therapy for metastatic breast cancer". The article did not undergo external peer review.

Conflicts of Interest: Both authors have completed the ICMJE uniform disclosure form (available at http://dx.doi.org/10.21037/ tcr-2020-mbc-13). The series "Loco-regional therapy for metastatic breast cancer" was commissioned by the editorial office without any funding or sponsorship. TS served as the unpaid Guest Editors of the series and also serves as an unpaid editorial board member of Translational Cancer Research from Aug 2019 to Jul 2021. KT served as the unpaid Guest Editors of the series. The authors have no other conflicts of interest to declare.

Ethical Statement: The authors are accountable for all aspects of the work in ensuring that questions related to the accuracy or integrity of any part of the work are appropriately investigated and resolved.

Open Access Statement: This is an Open Access article distributed in accordance with the Creative Commons Attribution- 
NonCommercial-NoDerivs 4.0 International License (CC BY-NC-ND 4.0), which permits the non-commercial replication and distribution of the article with the strict proviso that no changes or edits are made and the original work is properly cited (including links to both the formal publication through the relevant DOI and the license). See: https://creativecommons.org/licenses/by-nc$\mathrm{nd} / 4.0 \%$.

\section{References}

1. Paget S. The distribution of secondary growths in cancer of the breast. Lancet 1989;133:571-3.

2. Schmid P, Adams S, Rugo HS, et al. Atezolizumab and Nab-Paclitaxel in Advanced Triple-Negative Breast Cancer. N Engl J Med 2018;379:2108-21.

3. Hortobagyi GN. Treatment of breast cancer. N Engl J Med 1998;339:974-84.

4. Shien T, Iwata H. Significance of primary lesion resection in Stage IV breast cancer. Jpn J Clin Oncol 2017;47:381-4.

5. Niikura N, Costelloe CM, Madewell JE, et al. FDG-PET/CT compared with conventional imaging in the detection of distant metastases of primary breast cancer. Oncologist 2011;16:1111-9.

6. Pagani O, Senkus E, Wood W, et al. International guidelines for management of metastatic breast cancer: can metastatic breast cancer be cured?. J Natl Cancer Inst 2010;102:456-63.

7. Hojo T, Masuda N, Mizutani T, et al. Intensive vs. Standard Post-Operative Surveillance in High-Risk Breast Cancer Patients (INSPIRE): Japan Clinical Oncology Group Study JCOG1204. Jpn J Clin Oncol 2015;45:983-6.

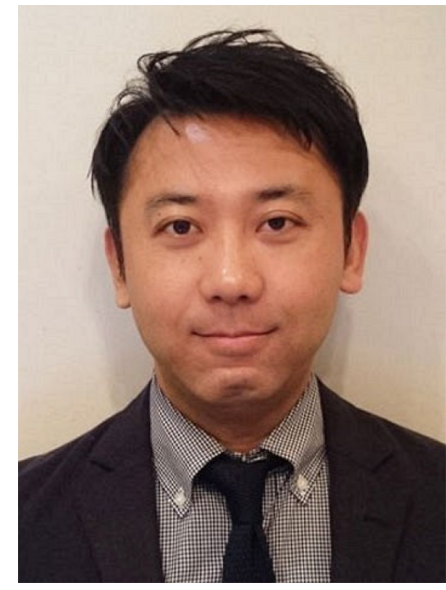

Tadahiko Shien

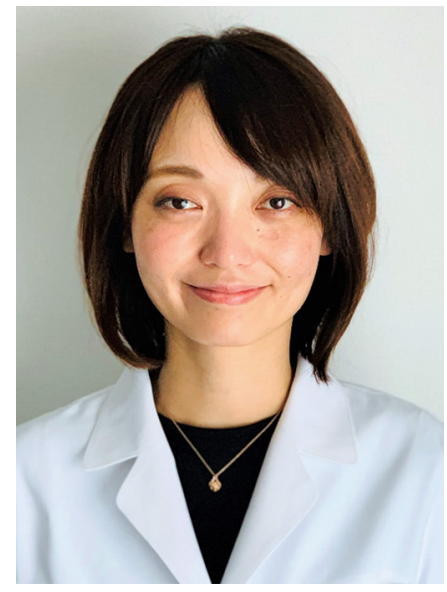

Kaori Terata

Tadahiko Shien

Department of Breast and Endocrine Surgery, Okayama University Hospital, Okayama, Fapan. (Email: tshien@md.okayama-u.ac.jp) Kaori Terata Department of Breast and Endocrine Surgery, Akita University Hospital, Akita, Fapan. (Email: trt0605@gipc.akita-u.ac.jp) Submitted May 26, 2020. Accepted for publication Jun 19, 2020. doi: $10.21037 /$ tcr-2020-mbc-13 View this article at: http://dx.doi.org/10.21037/tcr-2020-mbc-13

Cite this article as: Shien T, Terata K. Loco-regional therapy for metastatic breast cancer. Transl Cancer Res 2020;9(8):5026-5027. doi: $10.21037 /$ tcr-2020-mbc-13 